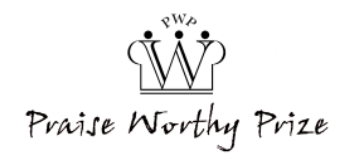

\title{
Safety of Aircraft Structures in the Context of Composite Element Connection
}

\author{
R. Bielawski ${ }^{1}$, W. Rządkowski ${ }^{2}$, M. Kowalik ${ }^{2}$, M. Kłonica ${ }^{3}$
}

\begin{abstract}
Recently, there has been a growing trend towards an ever greater use of composite materials in aircraft structures. This necessitates a search for effective ways of joining these materials. The desirable characteristics of such joints are predominantly high strength and low mass, both of which are features offered by rivet nuts. The study was conducted on one type of glass fabric material, from which two types of composite specimens were prepared. Each specimen used the same type of fibre of the same number of 3 layers, yet of different lay-up. Specimens were joined with aluminium alloy and steel rivet nuts to produce single and multi-row parallel models of riveted joints for further testing and analysis. The specimens were clamped in the grips of tensile machine and subjected to a tensile strength test. In the work, the course of the forces in the rivet nuts joint and the failure modes and effects of joint failure were analysed. The distribution of vertical displacement was examined according to the joint material and two fibre orientation variants. To determine the distribution of displacements, the FE (Finite Element) method was used. Upon completion of the experimental stage, the obtained results were subjected to comparative analysis. Copyright $\odot 2020$ The Authors.

Published by Praise Worthy Prize S.r.l.. This article is open access published under the CC BY-NC-ND license (http://creativecommons.org/licenses/by-nc-nd/3.0/).
\end{abstract}

Keywords: Laminates, Damage Mechanics, Mechanical Testing, Joints/Joining

\section{Introduction}

Composite materials are widely used in manufacturing, e.g. in aerospace applications, owing to their high specific strength and stiffness. The use of composites plays an increasingly important role in the development of aircraft and astronautic technology. The constant development of the composite technology has gradually led to their application in integrated composite aerostructures, with the major advantages of the method including: a reduction in the number of parts and the primary structural weight assembly cost e.g., in civil aircraft, the number of composite elements in an American Boeing 787 amounts to $50 \%$ of the total number of parts, and in military aircraft, the composite structure has been used in the forward fuselage of the American F-35 Joint Strike Fighter; furthermore, a cocured skin structure and vertical web are used in the European EP-2000 with a view to substantially improving the validity and reliability of the structural integrity of the aircraft [1]. There are two leading joining methods used in composite structures: mechanical and adhesive [2], [3]. Riveting remains one of the main joining methods in thin-walled aircraft structure applications. There are several reasons for the lasting popularity of riveting: simplicity of implementation, possibility of connecting heterogeneous materials (e.g. metallic with non-metallic ones) and the fact that it is a well-established (and reliable) method. The persistent striving to obtain as low mass as possible (mainly to reduce fuel consumption) is the reason for using material of high specific strength in the aerospace industry [4].

Mechanical joints, such as riveting, have several advantages and disadvantages compared to adhesively bonded joints, such as: in joining composite parts, mechanical joining requires rivets or/and bolts through holes, which introduces stress concentrations, ultimately leading to possible failure, whereas adhesive joints do not require holes and they distribute the load over a larger area than mechanical joints. However, they are highly sensitive to surface treatment, operating temperatures, humidity, and other environmental conditions [5].

\section{Research Methodology}

\section{II.1. Review and Aim of Study}

Currently, there are many publications in the literature on composites using in aviation manufactures [6]-[8] and mechanical composite joining [1], [2], [9], [10]. There are few publications on joining by means of rivet-nuts [11]. There are also no models of FE rivet-nut joints. The aim of this study was to determine the feasibility of riveted joints of composites. The paper focuses on Glass Fibre Reinforced Plastic (GFRP) composites in the context of joining by means of riveted joints of two types of rivet nuts. The tensile tests were conducted to analyse force $\mathrm{v}$ displacement in composite joints and the effect of 
damage models developed in the materials. Numerical models were built and enabled the distribution of vertical displacement to be obtained. Conclusions are presented at the end of the work.

\section{II.2. Composite Specimen Preparation}

Specimens were made of Interglas 92140, a heavyweight twill cloth certified for the aircraft industry, of twill $2 \times 2$ structure and high density and weight $(2.55$ $\mathrm{g} / \mathrm{cm}^{3}$ and $390 \mathrm{~g} / \mathrm{m}^{2}$ respectively). Each specimen used the same type of fibre of the same number of 3 layers, yet of different lay-up. The composite specimens were created of oblique and parallel/perpendicular fibres and were fabricated by the hand lay-up technique [12] in an autoclave, according to the manufacturer's recommended curing procedure. Two series of specimens were prepared, differing in terms of fibre orientation. Table I shows the data from the specimens for ordering purposes.

In the process of lamination, the adhesive epoxy resin Epidian 53 was combined with Z-1 hardener at a 10:1 ratio by weight. Upon application of the adhesive, the specimens were subjected to heat treatment to improve their mechanical properties. The post-cure process followed the recommended time and lasted for 8 hours at $60{ }^{\circ} \mathrm{C}$. The volume-fibre ratio was established, and was estimated at approx. 58\%. The test samples' (Fig. 1) dimensions were $220 \times 100 \mathrm{~mm}$ and thickness of approximately $1 \mathrm{~mm}$. Rivet holes of $\varnothing 6 \mathrm{~mm}$ diameter were drilled in the middle of the test area. The distance between the centres of the holes (pitch) was constant $20 \mathrm{~mm}$. The length between the edge of specimens and centres of the rivet holes was equal to $50 \mathrm{~mm}$. The test area dimensions were $120 \times 100 \mathrm{~mm}$. The fixed part of the specimen was placed in the tensile machine.

The joint formed with two GFRP composite specimens with the same fibre orientation was produced with a single-riveted joint (Fig. 2) in a single-lap model.

Between one and three rivet nuts were used in each joint. The rivet nuts dimensions were M4/ $\varnothing 6$, and were made of two different materials - aluminium alloy (AlMg5) and zinc steel (St).

TABLE I

DESCRIPTION OF TEST SAMPLES

\begin{tabular}{|c|c|c|c|}
\hline Fibreglass type & Orientation Icon & Series number & Laminate code \\
\hline \multirow{2}{*}{ Interglas 92140} & & I & {$\left[-45_{2} / 45\right]_{S}$} \\
\hline & I & II & {$\left[0_{2} / 90\right]_{S}$} \\
\hline
\end{tabular}

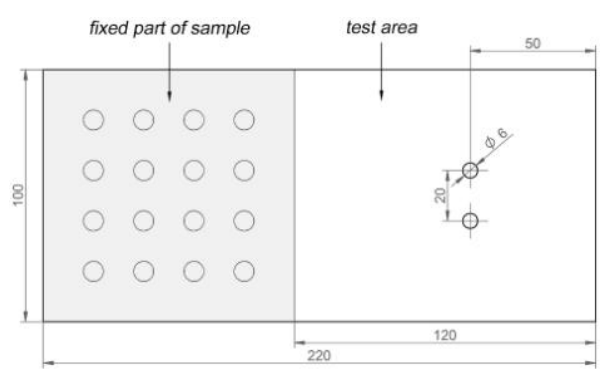

Fig. 1. Geometry parameters of the sample

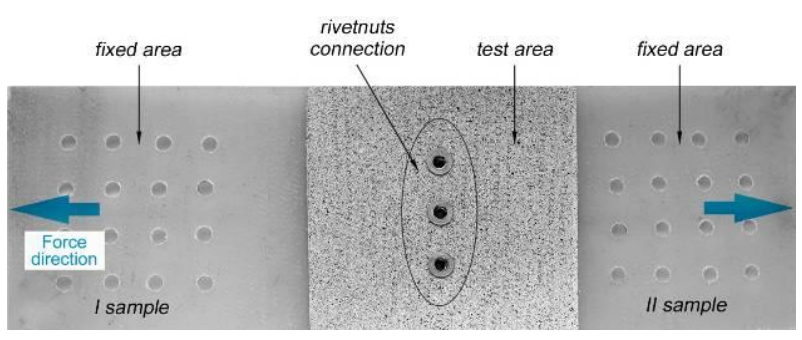

Fig. 2. Rivet-nuts connection between composite samples

\section{II.3. Test Procedure}

The aim of the experiment was to conduct a series of tests on the tensile machine INSTRON 8516. The rivet nut joint samples were subjected to a tensile load applied at a speed of $0.05 \mathrm{~mm} / \mathrm{s}$ and to a distance of up to 10 $\mathrm{mm}$. During the tensile test, the displacement and the pull force were registered. Three types of riveted joints, differing in the number of rivet nuts and type of substrate material (aluminium and steel), were tested in the experiment.

\section{Analysis of Tests Results}

\section{III.1. Force Analysis}

Pull force $\mathrm{v}$ displacement for connections depending on the type of rivet nuts is shown below. For aluminium (Figs. 3) and steel (Figs. 4), rivet nut graphs were shown.

Diagrams for aluminium fasteners depending on fibre orientation (series I and II) for one up to three rivet nuts are also included below (Figs. 3 (a)-(c)). In general, the curves show a distinct division into three parts. Firstly, the graphs show a clear inflection point near the middle of their length. The first part of the curve shows a large inclination angle, which indicates high stiffness modulus in joined composite specimens. Secondly, the stiffness modulus is smaller.

The shape of the curve for each configuration of the fibre orientation and the number of rivet nuts is similar. When using a combination of one and two rivet nuts, depending on the fibre orientation, the failure (the shear of rivet nuts) occurred at a displacement of approx. 3.5-4 $\mathrm{mm}$. This distance shows some dependence on the acting force. Variations in the force of each series circuit, depending on the fibre orientation, are negligibly small (approx. $80 \mathrm{~N}$ ). Generally, after reaching the maximum value, a drastic drop in force was observed until it reached zero (approximately zero). The final drop in force corresponds to joint failure, the force to flatten the walls and, consequently, to produce shearing of the rivet nuts. The vertical line indicates that a single rivet failure occurs at the same time and it depends on the number of rivets.

The force acting on the joint was therefore distributed throughout the joint, and not carried by a single rivet.

Graphs for steel rivet nuts depending on fibre orientation (series I and II) for one-to-three rivet nuts can be viewed in Figures 4(a)-(c). 


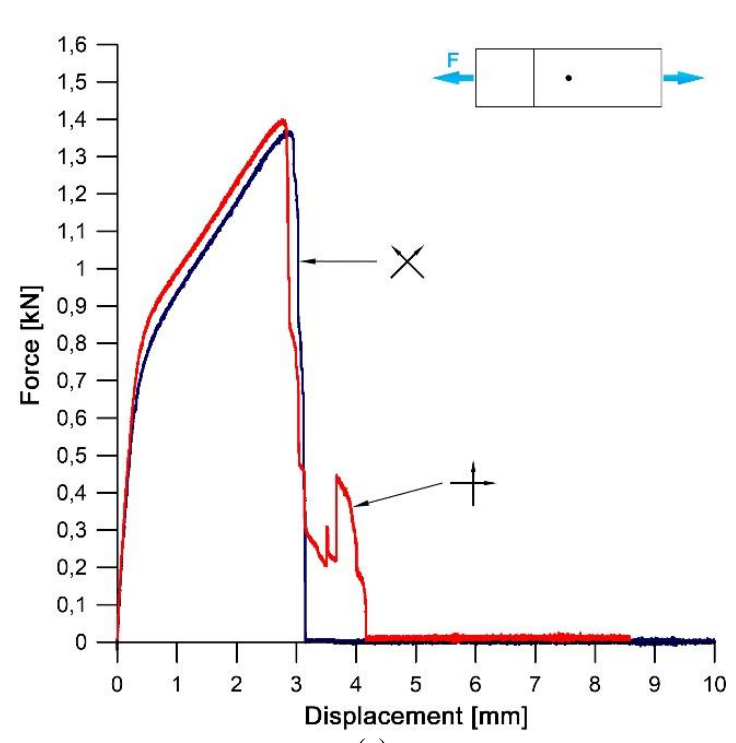

(a)

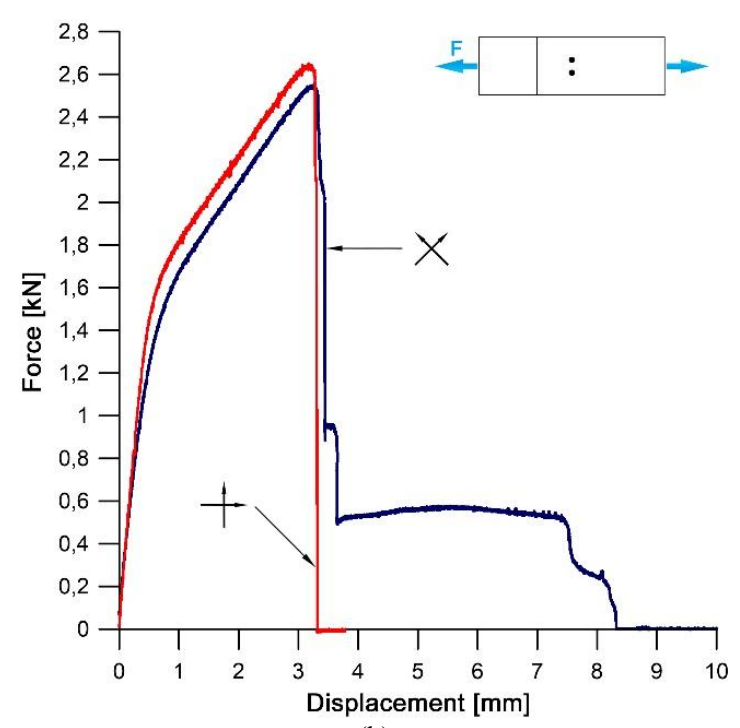

(b)

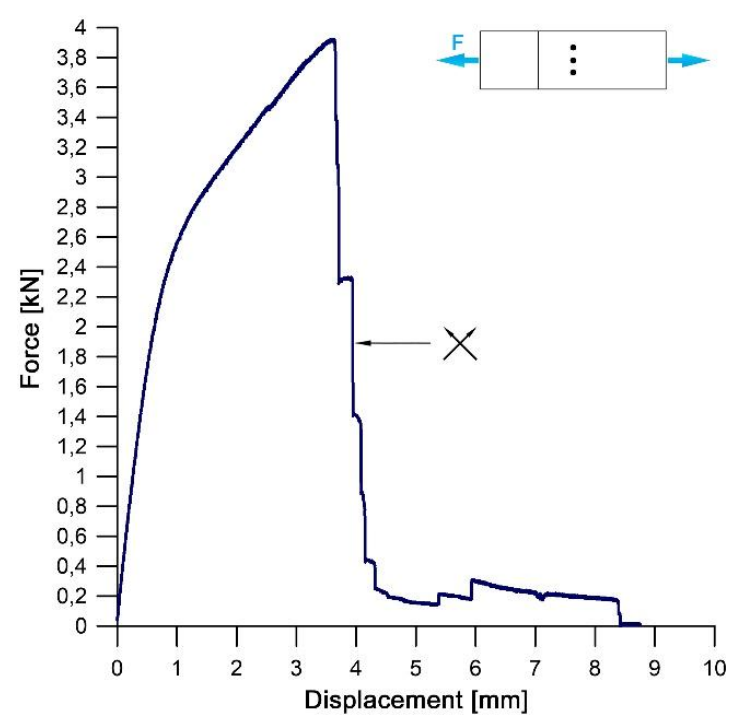

(c)

Figs. 3. Pull force vs. displacement for samples (“X” and “+” fiber orientation) for alloy aluminum rivet-nuts for

(a) 1 rivet-nut; (b) 2 rivet-nuts; (v) for 3 rivet-nuts

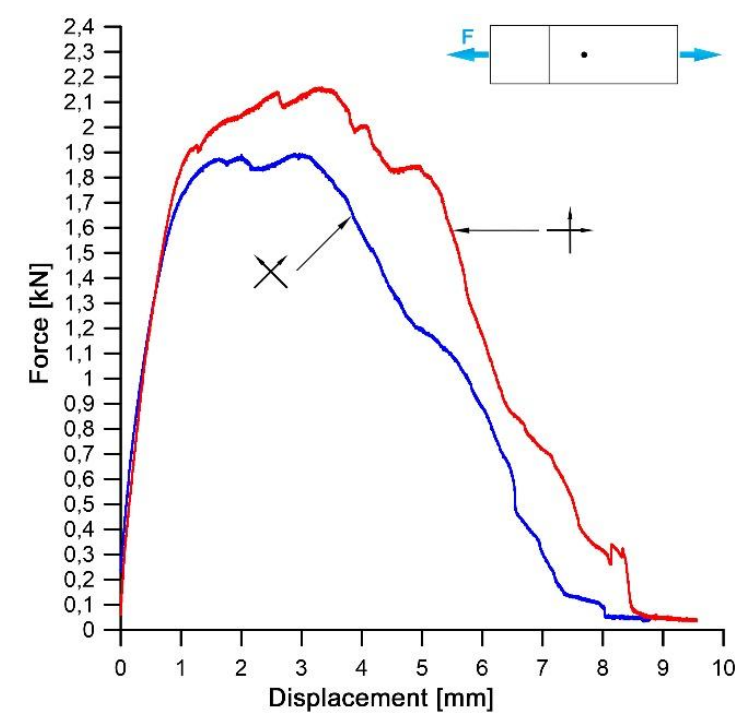

(a)

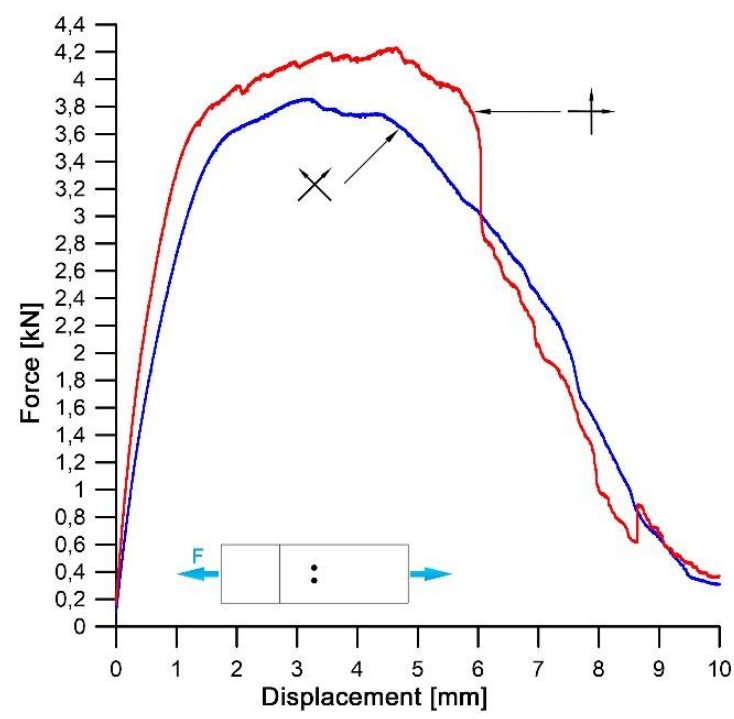

(b)

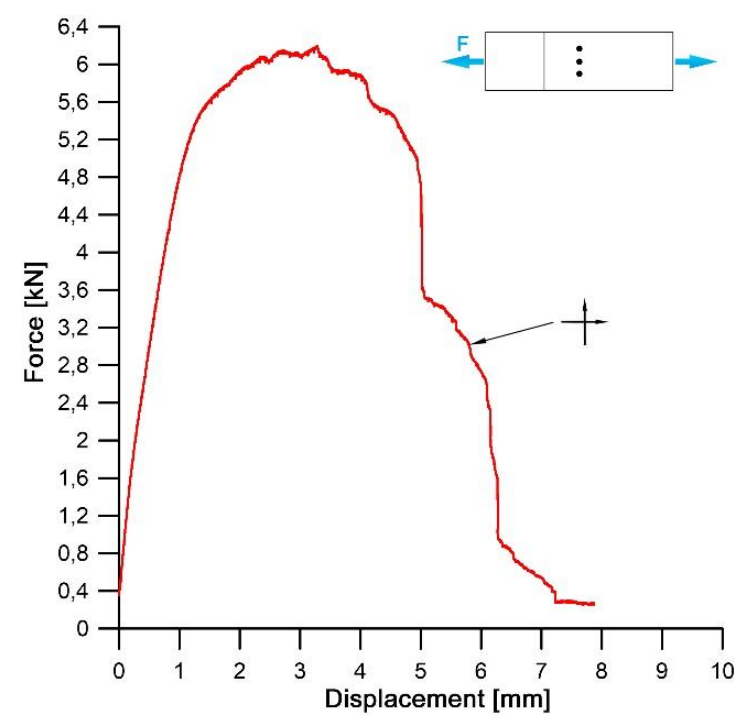

(c)

Figs. 4. Pull force vs. displacement for samples (" $X$ " and "+" fiber orientation) for steel rivet-nuts for (a) 1 rivet-nut; (b) 2 rivet-nuts; (v) for 3 rivet-nuts

International Review of Aerospace Engineering, Vol. 13, N. 5 
The three-step process is noticeable. In the first phase, the diagram shows the rapid quasi-linear increase of the force to the point of its inflection. It probably defines the phenomenon of rupture of the boundary layer (the First Ply Failure - FPF [13]). The second phase of the curve is between the point of FPF and the next point of its inflection: it represents the limit at which the composite destruction is connected with the transmission by a combination of forces. Between the characteristic points of inflection, the function reaches its maximum. The third cycle of the curve is a rapid decline in the value of power together with the lack of its portability by the examined rivet nuts connection. The phenomenon of the rapid decline in the value of the force is due to disconnects. The comparison of curves, depending on the orientation of fibres, leads to two observations. In test series II (red colour), rigidity is greater - a greater angle of inclination to the axis $0 x$ of the first phase of the curve (quasi-linear increase in the force). Specimens of this test series exhibit higher values of the maximum force. Their differences for the same number of connectors between the first and the second test series are respectively -260 and $440 \mathrm{~N}$. It may also be noted that the values of maximum forces, relative to the number of connectors, are dependent in such a way that they are approximately the product of their number and the maximum power for a single joint.

The maximum force values for aluminium and steel rivet nuts are summarised in the following table (Table II).

Based on maximum values collected in the table, it can be concluded that for test series II, the maximum forces are higher and do not depend on the type of rivet nut material. The differences in the results are greater for steel fasteners and averages $80 \mathrm{~N}$ for aluminium joints, and about $350 \mathrm{~N}$ for steel rivet nuts. Generally, the maximum forces for steel fasteners are $40 \%$ higher compared to the aluminium joints. Despite the significant difference in weight $(\mathrm{AlMg} 5=1.55 \mathrm{~g}, \mathrm{St}=0.53 \mathrm{~g})$, it gives the designer an alternative choice. In the case of aircraft structures, which may necessitate using as many as 1 million of such fasteners, the selection of joint type is decisive to the mass of the structure.

\section{III.2. Failure Analysis}

In composite materials, four types of failure modes can be identified, such as: bearing (B), net-section (NT), shear-out (S) and cleavage (C) [14]-[16].

TABLE II

MAXimum Force VALUeS DEPENDING ON THE Number OF FASTENERS AND TYPES OF RIVET NUTS

\begin{tabular}{cccc}
\hline \hline \multirow{5}{*}{ Series number } & \multicolumn{4}{c}{ Max force values [kN] depending on number the of } \\
& 1 rivet nut & 2 rivet nuts & 3 rivet nuts \\
\hline \multicolumn{5}{c}{ AlMg5 rivet nuts } \\
I & 1.89 & 3.85 & - \\
II & 2.15 & 4.29 & 7.87 \\
\multicolumn{4}{c}{ St rivet nuts } \\
I & 1.40 & 2.45 & 3.90 \\
II & 1.35 & 2.62 & - \\
\hline \hline
\end{tabular}

Figures 5 show the consequences of failure in the tested composite joints. Figure 5(a) shows the failure of AlMg5 joint connectors. Here, bearing (B) occurred, caused by the connector bush. As a result, it was disconnected by rivet nut shear. Composites remained without visible external damage and rivet holes in probes and the surrounding area were not destroyed.

Figure 5(b) shows the types of failure, which in the analysed case concern composite samples. There are clear signs of a number of fibre breakages, local delamination and cracking of the matrix with propagation along the direction of reinforcement. The connector in this joint shows no visible damage.

\section{III.3. Displacements Analysis}

In the presented work, the Finite Element (FE) method was used to determine vertical displacements (Ey). The 3D models of joints of GFRP composite materials were formed by means of rivet nuts composed of three laminates of $0.36 \mathrm{~mm}$ thickness. The contact (rivet hole fasteners) with coefficient friction $\mu=0.25$ was modelled. The model also included the preload, corresponding to the connectors' clamping force. The model employed 3D SOLID186 elements defined by 20 nodes with three degrees of freedom per node.

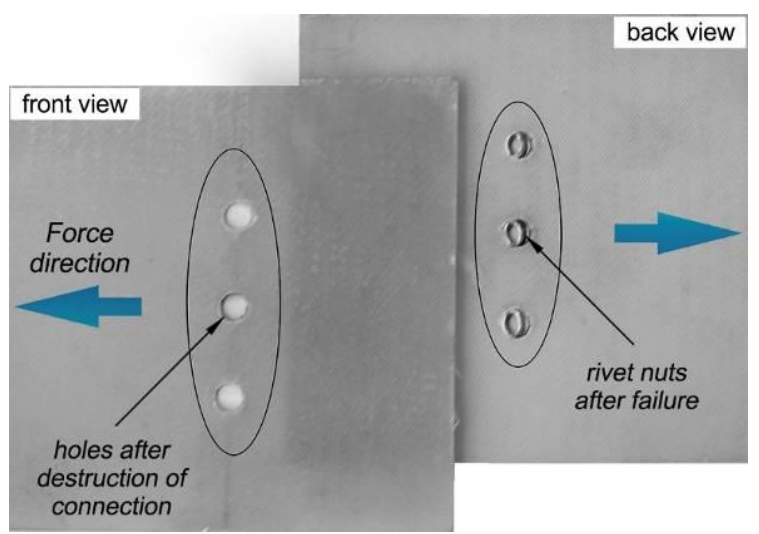

(a)

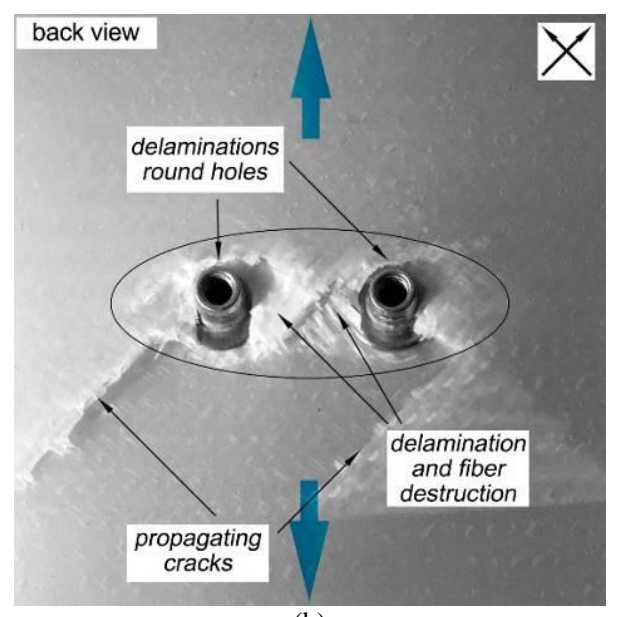

(b)

Figs. 5. Damage of connection for (a) aluminum fasteners (b) steel rivet-nuts 
In discretisation, the analysed area was divided freely, with the density of the area around a previously defined contact. The results of the analysis, depending on the fibre orientation and that of the rivet nut material, are shown on maps with vertical displacement in the figure below (Figs. 6). The maps were generated for quasimaximum pull force, obtained from the experiments.

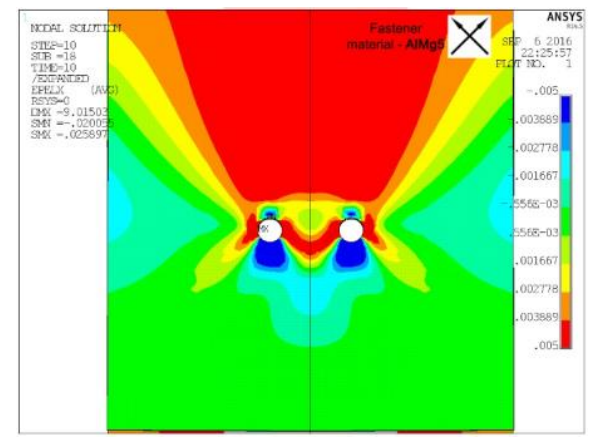

(a)

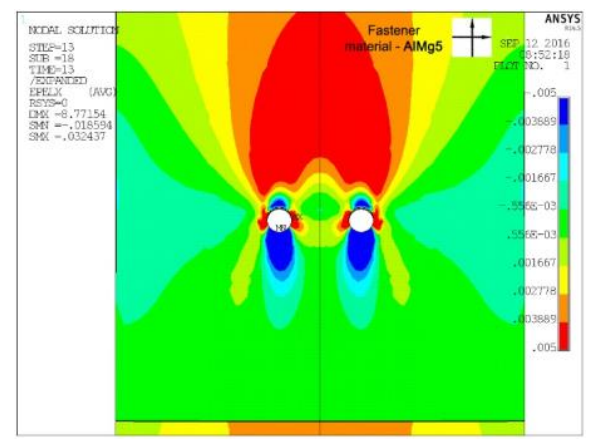

(b)

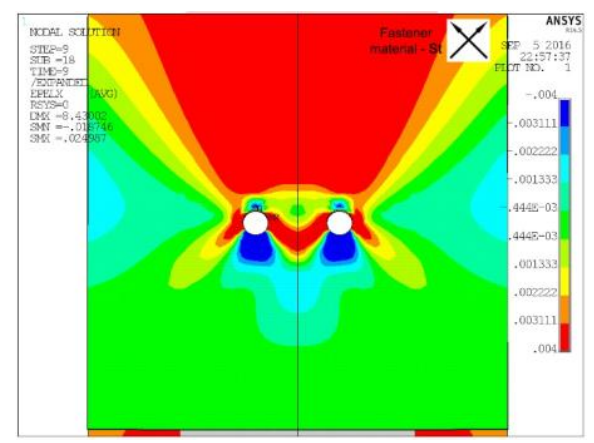

(c)

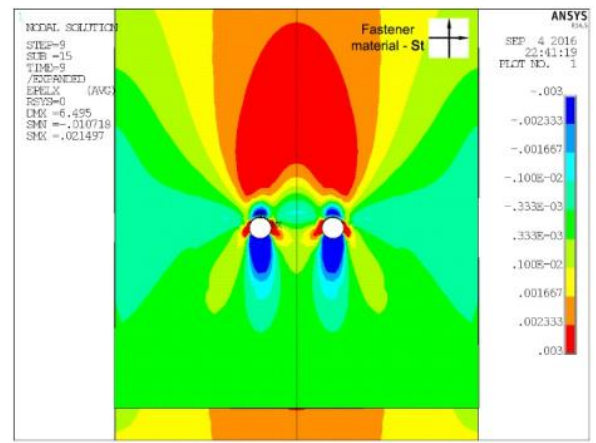

(d)

Figs. 6. Distribution of vertical displacements ( $\varepsilon y)$ depending on fiber orientation and fasteners material for (a) aluminium, I series; (b) aluminium, II series; (c) steel, I series; (d) steel, I series
The results do not exhibit any significant changes regarding the fastener material; however, differences occurred with respect to the orientation of the reinforcement. Series I of the test samples shows a larger tension area above the joint compared to series II (compare Figs. 6(a), (c) and Figs. 6(b) (d)). Characteristic displacement distributions of oblique fibres corresponded to the orientation of fibres. In both series, there is a clearly visible material compression in the area above the rivet holes, which was caused by the deformation of the rivet nut collar. The compression is also present below the fasteners. For series I, deformation is elongated, while in series II it is shallower and wider. The observed distribution patterns result from the directional reinforcement of the laminate material. Extreme (maximum and minimum values) vertical displacement of composite connections recorded in each series and material fasteners are collated in Table III. The results appear to show a general tendency for the steel fastener to succumb to a greater extreme displacement than the aluminium rivet nut; furthermore, the recorded displacement values are also higher in test series I. The discrepancy in results (between series I and II) could be safely attributed to fastener material and fibre direction used in tested laminates.

TABLE III

EXTREME VERTICAL DISPLACEMENT OF COMPOSITE JOINTS IN SERIES AND FASTENER MATERIAL

\begin{tabular}{ccc}
\hline \hline \multirow{2}{*}{ Series number } & \multicolumn{2}{c}{ Displacement $(\varepsilon y)$} \\
& $\min$ & $\min$ \\
\hline \multirow{3}{*}{ I } & AlMg5 rivet nuts & \\
II & -0.02 & 0.0258 \\
& -0.0185 & 0.0324 \\
I & St rivet nuts & \\
II & -0.0187 & 0.0249 \\
\hline \hline
\end{tabular}

\section{Conclusion}

The choice of rivet nut material leads to differences in force diagrams as a function of crosshead displacement of the tensile testing machine. For aluminium rivet nuts, the diagrams show joint failure. For steel rivet nuts, it is the connection material, i.e. the composite which fails. Maximum values recorded in tests prove that rivet nuts show considerable potential for use in industrial applications including the aerospace industry and as fasteners in aerostructures. As regards the strengthweight ratio of the connectors, whether they should be applied in a particular case remains a designer's decision.

It was shown that in the case of aluminium rivet nuts; this is the connector that is likely to be destroyed, whereas in steel fasteners it is the composite material.

The mechanical damage and delamination propagation in this case are equally dangerous for the joint structure, which is a critical characteristic for the aerostructure applications in particular. The FE method, employed to compare the distribution of vertical displacement in the composite materials showed that the distribution is largely dependent on the tested laminates' fibre 
orientation, whereas the connector material shows a lesser effect. Work will be continued towards damage prediction and into establishment and practical application of destruction criteria.

\section{References}

[1] X. Ma, K. Bian, J. Lu, K. Xiong, Experimental research on detection for interface debond of CFRP T-joints under tensile load. Compos Struct 2016;158:359-68. doi: https://doi.org/10.1016/j.compstruct.2016.09.006

[2] M. Roy Choudhury, K. Debnath, Experimental analysis of tensile and compressive failure load in single-lap adhesive joint of green composites. Int J Adhes Adhes 2020;99:102557. doi: https://doi.org/10.1016/j.ijadhadh.2020.102557

[3] M. Kirsnytė, M. Jurkūnas, Ž. Kancleris, P. Ragulis, R. Simniškis, A. Vareikis A, et al. Investigation of in situ formed conductive polymer composite in adhesive matrix. Synth Met 2019;258:116181.

doi: https://doi.org/10.1016/j.synthmet.2019.116181

[4] K. Puchała, E. Szymczyk, J. Jachimowicz, P. Bogusz, Gradient material model in analysis of mechanical joints of CFRP laminate, AIP Conference Proceedings 1922, 050006 (2018). doi: https://doi.org/10.1063/1.5019060

[5] R. M. Christensen, Failure criteria for fiber composite materials, the astonishing sixty year search, definitive usable results. Compos Sci Technol 2019;182:107718. doi: https://doi.org/10.1016/j.compscitech.2019.107718

[6] A. Baroutaji, T. Wilberforce, M. Ramadan, A. G. Olabi, Comprehensive investigation on hydrogen and fuel cell technology in the aviation and aerospace sectors. Renew Sustain Energy Rev 2019;106:31-40. doi: https://doi.org/10.1016/j.rser.2019.02.022

[7] J. Sun, C. Liu, H. Du, J. Tong, Design of a bionic aviation material based on the microstructure of beetle's elytra. Int J Heat Mass Transf 2017;114:62-72 doi. https://doi.org/10.1016/j.ijheatmasstransfer.2017.06.043

[8] A. Gisario, M. Kazarian, F. Martina, M. Mehrpouya, Metal additive manufacturing in the commercial aviation industry: A review. J Manuf Syst 2019;53:124-49. doi: https://doi.org/10.1016/j.jmsy.2019.08.005

[9] R. Bielawski, M. Kowalik, K. Suprynowicz, W. Rządkowski, P. Pyrzanowski, Investigation of Riveted Joints of Fiberglass Composite Materials. Mech Compos Mater 2016;52:199-210. doi: https://doi.org/10.1007/s11029-016-9573-4

[10] H. Jiang, Y. Cong, J. Zhang, X. Wu, G. Li, J. Cui, Fatigue response of electromagnetic riveted joints with different rivet dies subjected to pull-out loading. Int J Fatigue 2019;129:105238. doi: https://doi.org/10.1016/j.ijfatigue.2019.105238

[11] S. Hassanifard, M. R. Adibeig, M. Mohammadpour, A. VarvaniFarahani, Fatigue life of axially loaded clamped rivet-nut joints: Experiments and analyses. Int J Fatigue 2019;129:105254. doi: https://doi.org/10.1016/j.ijfatigue.2019.105254

[12] Anwar, A., Osman, M., Elfiky, D., Hassan, G., Performance Evaluation of Selected Irradiated Space Structure Composites Manufactured by the Hand Lay-Up Method, (2018) International Review of Aerospace Engineering (IREASE), 11 (4), pp. 155-161. doi: https://doi.org/10.15866/irease.v11i4.13726

[13] [T. Y. Kam, H. M. Su, C. Y. Huang, Quasi-static buckling and first-ply failure loads of shear web reinforced glass-fabric composite wind blades. Compos Struct 2017;160:1225-35. doi. https://doi.org/10.1016/j.compstruct.2016.10.087

[14] H. Rezaeian, G. C. Clifton, J. B. P. Lim, Failure modes for composite steel deck diaphragms subjected to in-plane shear forces - A review. Eng Fail Anal 2020;107:104199. doi: https://doi.org/10.1016/j.engfailanal.2019.104199

[15] Anish, A. Kumar, A. Chakrabarti, Failure mode analysis of laminated composite sandwich plate. Eng Fail Anal 2019:104:950-76. doi: https://doi.org/10.1016/j.engfailanal.2019.06.080

[16] A. Kubit, T. Trzepiecinski, M. Kłonica, M. Hebda, M. Pytel, The influence of temperature gradient thermal shock cycles on the interlaminar shear strength of fibre metal laminate composite determined by the short beam test. Compos Part B Eng 2019;176:107217.

doi: https://doi.org/10.1016/j.compositesb.2019.107217

\section{Authors' information}

${ }^{1}$ Military University of Technology, Faculty of Security, Logistics and Management, Warsaw, Poland.

${ }^{2}$ Warsaw University of Technology, Institute of Aeronautics and Applied Mechanics, Warsaw, Poland.

${ }^{3}$ Lublin University of Technology, Faculty of Mechanical Engineering, Lublin, Poland.

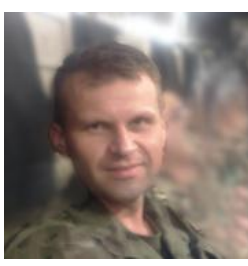

Radosław Bielawski, PhD Eng. was born 20.08.1980 in Ryki, Poland. Graduate from the Military University of Technology, National Defense University, Private School of Business, Administration and Computer Technology as well as Warsaw University of Technology. Research interests: aviation, mechanical engineering, security. Dr. Bielawski was Deputy Director of the Department of Security Fundamentals at War Studies University and Editor-in-Chief of the journal "Security and Defence Quarterly" (ISSN 2300-8741, eISSN 2544-994X). Expert at the National Center of Research and Development in the Smart Growth Operational Programme (SGOP).

E-mail: bielawski@meil.pw.edu.pl

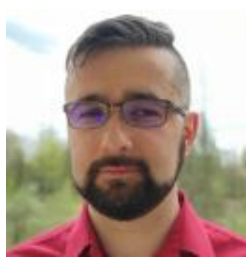

Witold Rządkowski (born in Bytom Poland, 1984) holds a master in engineering degree (Warsaw University of Technology, Warsaw, Poland, 2010) in Automation and Robotics and a doctorate in Mechanics (Warsaw University of Technology, Warsaw, Poland, 2015). His research interests include FEM analysis, experimental mechanics, advanced composite materials and additive manufacturing. Dr Rządkowski is an assistant professor at The Faculty of Power and Aeronautical Engineering at Warsaw University of Technology.

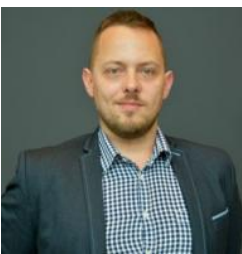

Michal P. Kowalik, was born in Warsaw Poland, 1984) holds an engineering degree (Warsaw University of Technology, Warsaw, Poland, 2006) and a master's degree (Warsaw University of Technology, Warsaw, Poland, 2009) in Automation and Robotics and a doctorate in Mechanics (Warsaw University of Technology, Warsaw, Poland, 2016). His research interests include solid body mechanics, experimental mechanics, advanced composite materials and additive manufacturing. Dr Kowalik is an assistant professor at The Faculty of Power and Aeronautical Engineering at Warsaw University of Technology.

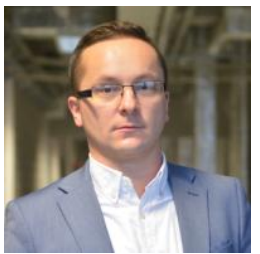

Mariusz Klonica, $\mathrm{PhD}$ Eng. was born 06.04.1980 in Ostrowiec Świętokrzyski. Department of Production Engineering, Faculty of Mechanical Engineering, Lublin University of Technology, 36 Nadbystrzycka Str., 20-618 Lublin, Poland. 